\title{
Research on Design and Construction Key Points of HVAC Engineering in Civil Engineering
}

\author{
Wang Feng ${ }^{1}$, Yin Dongpeng ${ }^{1,2}$ \\ ${ }^{1}$ Dalian Vocational and Technical College, Liaoning, China, 116035 \\ ${ }^{2}$ Dalian Institute of Urban and Architecture Design Co.,LTD
}

Keywords: Civil engineering; HVAC engineering; construction key points; analysis

\begin{abstract}
With the increase of the construction of modern residential areas and the continuous expansion of the area, the HVAC project has also developed rapidly. However, in the civil engineering, there are still some defects in the HVAC project. Therefore, how to effectively improve the construction of the HVAC project has become an important work content of the relevant building design and construction units. This paper mainly analyzes the importance of HVAC construction in civil engineering and deeply explores the key points and management of civil construction HVAC, hoping to help the construction of HVAC project.

The quality requirements of HVAC projects are very high and have a very important impact on residential buildings. If the idea of water leakage occurs after the construction of the house is completed and renovated, it will cause serious damage to the residential building. Among them, once there is a problem in the construction of a complex house such as a bathroom or a kitchen, the result will be very serious. It is very necessary to use strict construction operations to ensure the quality of civil engineering construction. Therefore, the relevant units must strictly control the construction quality of the HVAC project and require the operators to have skilled skills.
\end{abstract}

\section{Importance of HVAC construction in civil engineering}

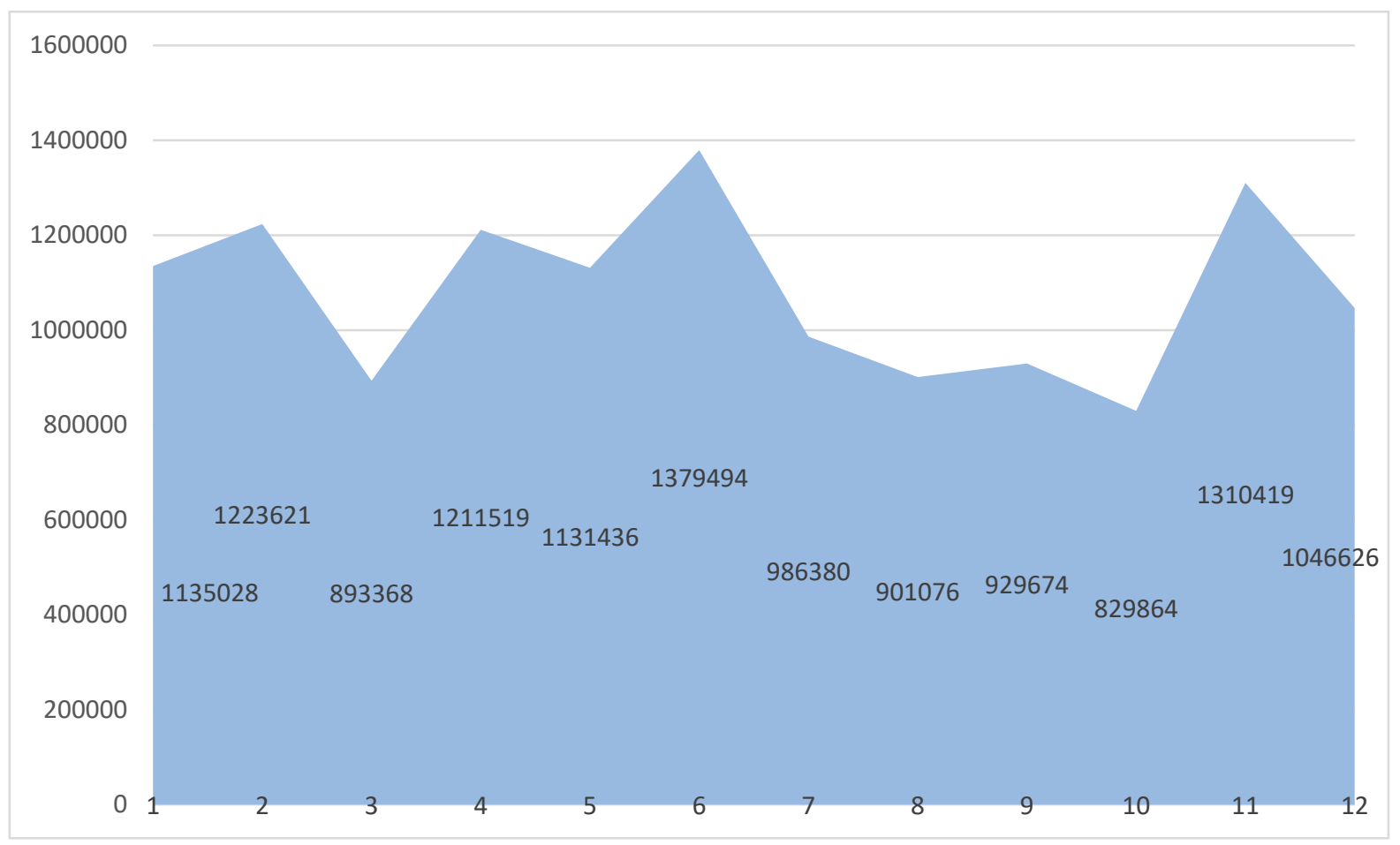

Figure 1 Material consumption of the HVAC

At present, the construction of HVAC projects in civil engineering is concentrated in the two aspects of heating and ventilation. There are two ways to heat, one is the old type of heating and the 
other is the new type of heating. The old-style heating method is to install a heating system in the residential area and use the heating to transmit warmth; the new heating method is geothermal, using advanced enemy technology to provide warmth to people. Ventilation refers to the ventilation system in both the kitchen and the bathroom. The continuous improvement of the level of modernization has driven people's quality of life. People have higher needs for the residential environment and ventilation engineering is increasingly becoming more user-friendly and convenient. As residential buildings are gradually upgrading the environment, higher requirements are placed on the interior design, which poses a major challenge to the construction of the HVAC project. Therefore, the HVAC project should fully improve the quality during construction, maximize the use time of the HVAC project and minimize the unnecessary maintenance costs of the HVAC project $^{[1]}$. The material consumption of the HVAC process throughout the year is shown in Figure 1.

\section{Design requirements and construction points of HVAC engineering in civil engineering}

\subsection{Design requirements for civil heating projects}

In order to be able to develop in the direction of practicality and green energy conservation, most of the heating systems installed in the HVAC project are geothermal heating. This geothermal heating system, while providing warmth to residents, can also achieve energy conservation, emission reduction and economic and environmental protection, thus occupying a very important position in the construction of civil engineering. For the construction of this HVAC project, we must firmly grasp the following aspects:

First, we must do a good job in the design of indoor heating projects. Under the premise of fully guaranteeing the quality of the heating equipment, a good geothermal pipe is used to lay the pipeline to avoid the situation that the geothermal heat dissipation is too fast and the normal operation of the geothermal system is ensured. When decorating a house, choose a floor with better heat resistance to prevent accidents and cause adverse consequences ${ }^{[2]}$.

Second, we must ensure the quality of the HVAC construction project in the sanitary shower. On the basis of choosing good material geothermal, the floor is also required to be effectively waterproof, to prevent water leakage and other phenomena, affecting the use of the entire house. At the same time, the construction department should pay attention to the distance between the geothermal layer and the waterproof layer to ensure that the geothermal layer will not be affected and cause unnecessary damage to the heating system.

Third, it is necessary to ensure the normal operation of the mortar program in the heating system. The quality of mortar construction has a very important influence on the heating system. Therefore, in the construction of the HVAC project, the quantity of required materials should be accurately processed and strictly arranged and the warming should be strengthened on the basis of ensuring the reasonable ratio of mortar. The project stores the thermal energy system. At the same time, the treatment work after the mortar is used should also be arranged in place, so that the water vapor generated during the use process cannot affect the quality of the HVAC project. It is best to use the polishing program to effectively treat it and effectively strengthen the HVAC project. The heat storage function $^{[3]}$.

Fourth, it is necessary to ensure that the HVAC project can operate normally in cold weather such as snow and rain. It is necessary to reduce the damage to the heating system caused by cold weather and prevent the occurrence of water pipe condensation, pipe cracking, etc. When the construction operator installs the HVAC equipment, it is necessary to carry out the relevant heating system cold test and carefully observe the water in the pipe. Whether it can be effectively eliminated, once an abnormality occurs, measures should be taken immediately to clear the pipeline to ensure the normal use of the pipeline.

\subsection{Analysis of construction points of HVAC engineering in civil engineering}

As we all know, the new heating system has many advantages such as energy saving and 
emission reduction, environmental protection and economy. Therefore, most of the residential heating areas in China have installed new heating systems, namely geothermal heating systems. In the construction process of this new heating system, the heating effect is concentrated from the following points. First of all, under the premise of ensuring that the floor can store heat, the heat loss in the heating system is effectively reduced. It is very advantageous to install a reflective film on the underside of the pipe and on the wall, especially the high-reflection film installed. It is more efficient to lay in the mezzanine of the bathroom floor. At the same time, there is no fear that the waterproof layer of the bathroom will be hurt. Some construction units will install the waterproof layer of the bathroom together with the geothermal layer, ignoring the distance between the two, resulting in serious damage to the waterproof layer or the geothermal layer. Secondly, if the construction of the HVAC project is carried out in cold weather, it should be noted that the ground is affected by the external low temperature and the water in the pipeline cannot be removed in time, which may cause blockage, rupture, or even warmth of the pipeline. The project caused damage. Therefore, after the installation is completed, the construction personnel should carry out relevant tests to discharge all the water in the pipeline to avoid freezing and cracking of the pipeline. Thirdly, a special corrugated pipe is installed in the joint portion of the heating pipe at the water separator, thereby reducing oxidation and damage of the pipe due to the denseness of the heating pipe and even possibly causing damage to the HVAC project, thereby saying that the pipe is Quality is very important. Finally, it is necessary to scientifically and rationally allocate the proportion of cement, sand and water: the proportion of water and sand has a great effect on the construction of geothermal heat and there should be no foam in the disposed mortar to prevent heat consumption and post-treatment of mortar. In the middle, it is necessary to carry out the polishing method. The quality of the mortar is directly dependent on the proportion of water, cement and sand. Therefore, the smearing measures in the post-treatment are effective guarantees for the geothermal heating system $^{[4]}$. The construction calculation process is shown in Figure 2.

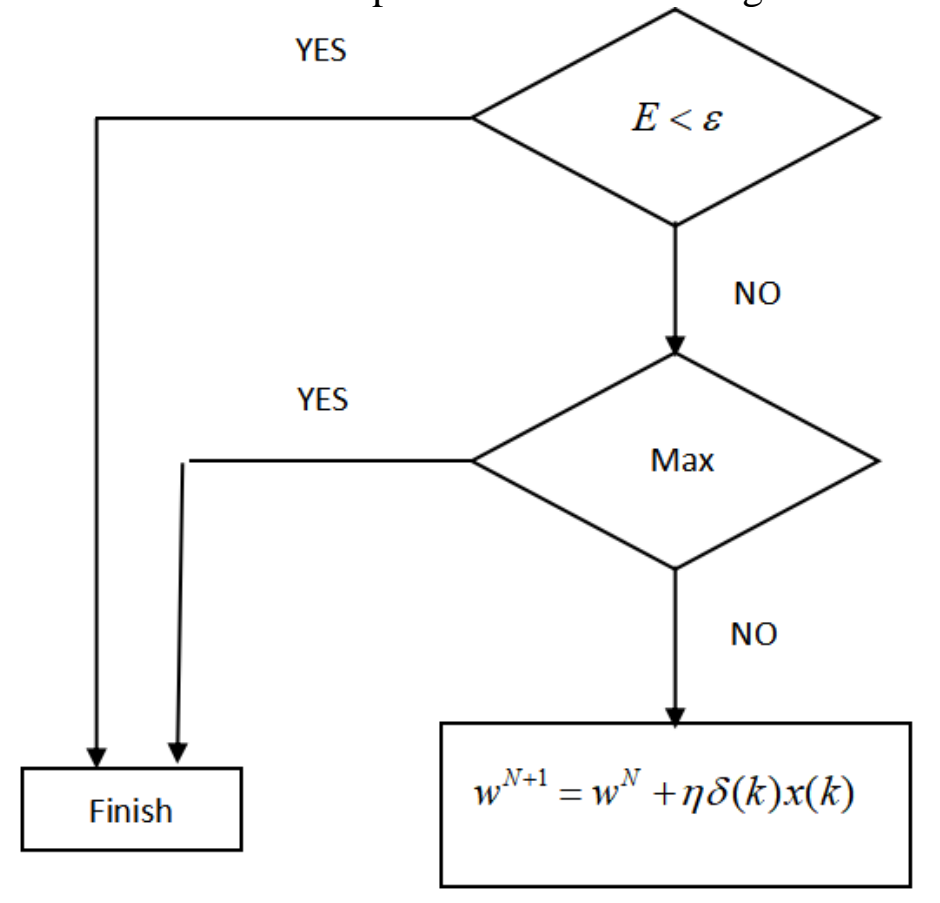

Figure 2 Construction calculation process

\subsection{Strengthen supervision management}

The importance of supervision work determines the quality of the construction of HVAC projects in civil engineering. At the same time, the level of technical skills of supervisors also has a great impact on the safety of the construction process. Strengthen the technical level of supervisors so that supervisors can identify potential safety hazards or existing problems during the actual construction process and make timely corrections. In addition, during the construction process, the 
quality used must be strictly checked and required to be inspected by professional inspectors before they can be put into use. For materials whose quality has not passed the inspection, they are not allowed to be used. Once the violation is found, they will be expelled immediately, strictly control the quality of raw materials and install high-quality civil engineering HVAC projects ${ }^{[5]}$.

\section{Conclusion}

The HVAC project of civil engineering buildings mainly appears in the northern part of China. Due to the obvious seasonal change in the northern region, the use of HVAC projects is relatively large. Therefore, improving the building quality of the HVAC project can play an important role in ensuring the long-term use of the people and promote the quality of life of the people. In summary, in the construction of HVAC projects in civil engineering buildings, it is necessary to ensure the design and construction quality of the project and avoid cost waste caused by re-maintenance. Facing the construction problems of HVAC projects in civil engineering buildings, focusing on problem-solving measures, improving building quality, strictly managing engineering construction and making efforts to improve people's quality of life.

\section{Acknowledgements}

Fund Project: national key R \& D Program for the Thirteenth Five-Year Plan "Evaluation of performance and Energy consumption of ventilation and Air purification and filtering Systems in Residential buildings" (No. 2016YFC0700503)

\section{References}

[1] KIRIBAYASHI Seiga, YAKUSHIGAWA Kaede, NAGATANI Keiji. Design and Development of Tether Powered Multirotor System for Construction Machine[J]. The Proceedings of JSME annual Conference on Robotics and Mechatronics (Robomec),2017,2017(0).

[2] Kristof Crolla. Building indeterminacy modelling - the 'ZCB Bamboo Pavilion' as a case study on nonstandard construction from natural materials[J]. Visualization in Engineering,2017,5(1).

[3] Warren Hornsey, Bill Service. A major failure involving an exposed geotextile to contain dredged spoil[J]. Geotextiles and Geomembranes,2017,45(5).

[4] A.L.C. Ciribini,S. Mastrolembo Ventura,M. Paneroni. Implementation of an interoperable process to optimise design and construction phases of a residential building: A BIM Pilot Project[J]. Automation in Construction,2016,71.

[5] Zhongkui Li,Baoqi Lu,Jing Zou,Bin Xu,Zhizeng Zhang. Design and operation problems related to water curtain system for underground water-sealed oil storage caverns[J]. Journal of Rock Mechanics and Geotechnical Engineering,2016,8(5). 